\title{
Microfoundations for Learning within International Joint Ventures
}

\section{Lead and corresponding Author:}

\section{Jeong-Yang PARK}

University of Edinburgh Business School

The University of Edinburgh

29 Buccleuch Place

Edinburgh EH8 9JS

United Kingdom

e-mail: jeongyangpark@hotmail.com

telephone: $+44(0) 7775934111$

fax: +44 (0)131650 8337

\section{Second Author:}

\section{Simon HARRIS}

University of Edinburgh Business School

The University of Edinburgh

29 Buccleuch Place

Edinburgh EH8 9JS

United Kingdom

e-mail: simon.harris@ed.ac.uk

telephone: +44 (0)7946 645069

fax: +44 (0)1316508337

This is a pre-print (non-publisher's document). Please cite this article as below:

Park, J-Y. and Harris, S. (2014) Microfoundations for learning within international joint ventures, International Business Review, 23: 490-503. 


\title{
Microfoundations for Learning within International Joint Ventures
}

\begin{abstract}
IJV research highlights the importance of learning in international joint ventures (IJVs) but has not indicated how to achieve it. We combine organizational learning and internationalization process research within a microfoundations framework to understand learning in IJVs. We study a Samsung-Tesco IJV that successfully learned retail practice from one partner and applied it in a South Korean context known by the other. The managers used many learning processes, not just experiential learning emphasized in international business research, and used many more knowledge sources than assumed in prior research, including the IJV partners' other subsidiaries. To build absorptive capacity, IJVs need appropriate microfoundations at individual, process and structural levels, and coherent interlinkages between them, especially by having IJV managers' with extensive experience and orientation to learn who are given structural and process autonomy to invest in learning.
\end{abstract}

\section{Highlights:}

- Learning in IJVs with dissimilar partners is best driven by autonomous IJV managers.

- Copying, recruitment and searching are important, not only experiential learning.

- Absorptive capacity building requires coherent links between levels of learning.

- Partner's other subsidiaries are important sources and recipients of learning.

Keywords: Learning, Microfoundations, Absorptive capacity, International joint venture

Acknowledgements: The authors would like to thank the journal's editor and three anonymous reviewers of this journal for their suggestions.

NOTE: Figures and tables have been placed within the text for the convenience of reviewers. They will be relocated if requested at a later stage. 


\section{Microfoundations for Learning within International Joint Ventures}

\section{INTRODUCTION}

International Joint Venture (IJV) research at firm and IJV partner levels has extensively highlighted the importance of learning in IJVs. IJVs offer a channel for learning opportunities (Park \& Ghauri, 2011) and provide a means of developing ventures that obtain knowledge, skills and competencies from partners with complementary capabilities (Beamish \& Berdrow, 2003; Inkpen, 2008; Kwon, 2008; Tsang, 2002). IJVs need to ensure appropriate learning processes because their capability to learn and diffuse accumulated knowledge stocks, flows and processes from their IJV partner firms is critical for their development (Beamish \& Berdrow, 2003; Park \& Ghauri, 2011); learning is their source of competitive advantage (Foss, Husted \& Michailova, 2010; Glaister, Husan, \& Buckley, 2003; Kandemir \& Hult, 2005). The difficulty of managing IJVs, where they face considerable barriers to knowledge transfer and learning in comparison with single firms (Pak et al., 2009), however, has been found to lead to a high failure rate (Beamish \& Delio, 1997; Pak, Ra, \& Park, 2009).

Little understanding has yet been gained, concerning how managers in IJVs achieve the learning that they need (Beamish \& Berdrow, 2003), despite increased interest in their management (Hyder \& Ghauri, 2000). There is a gap in research at the "micro-level" of IJV manager action and interaction (Foss et al., 2010), concerning the "microfoundations" of learning within IJVs. This study asks what are the capabilities, actions and decisions that help IJV managers to learn from their partners, to develop capability from that learning, and to build the absorptive capacity needed to do so. To do this, we take advantage of recent theoretical advances concerning the microfoundations of routines and capabilities to disentangle the underpinnings of organizational learning within IJVs. Drawing on the behavioral theory of the firm (Feldman \& Pentland, 2003; Winter, 2003), Felin, Foss, Heimeriks and Madsen (2012) have recently presented a framework for disentangling these microfoundations into individual, process and structural levels, and have noted that capacity building requires coordinated development within and between these levels.

We examine the structural, individual, and process microfoundations of the learning and absorptive capacity building undertaken at Homeplus, a well-known and highly successful retail IJV formed by Samsung and Tesco in pursuit of Tesco's internationalization strategy in Korea in 1999. Recent firm level studies of this IJV have noted that learning lay at the heart of its creation but have not identified how it was achieved (Coe \& Lee, 2006; Palmer, 2005; 
Suh \& Howard, 2009). This study examines how Homeplus managers engineered its success, and specifically, how Homeplus managers, mainly Korean Samsung employees, learned how to undertake world class retailing within the Korean setting that they knew well, and how Tesco as an organization learned how to overcome its liability of foreignness (Zaheer, 1995) in operating within Korea.

At individual level, we find that prior knowledge and experience, as well as the underlying educational level of the IJV managers appeared to help the absorptive capacity of the IJV and its speed of learning (Lane, Salk \& Lyles, 2001; Zahra \& George, 2002). At process level, experiential learning was important (Eriksson \& Chetty, 2003; Eriksson, Johanson, Majkgard \& Sharma, 2000; Johanson \& Vahlne, 1990), but so were other types of learning identified in organizational learning research, especially vicarious learning and grafting, mainly because of the managers' absorptive capacity developed from their previous experiential knowledge (Huber, 1991). Homeplus overcome substantial structural barriers to learning (Pak et al., 2009) by investing in intensive processes for developing effective absorptive capacity, by its managers having high levels of absorptive capacity as individuals, and by their having structural and process autonomy to drive the learning themselves.

We therefore found that Homeplus managers benefited from having the structural position, the process authority and the individual capability to source the knowledge they needed from where they could find it most readily, within and outwith the firms, and to implement it as they considered appropriate. This showed that all three sets of microfoundations are important, rather than the structural one that has hitherto been the focus of IJV research. Further, we also show how coherent linkages between the microfoundations of individuals, processes and structure are essential if absorptive capacity building is to be achieved within IJVs. The paper proceeds as follows: We first present the theoretical foundations, outlined above, and conclude by describing a research framework that informs the study. We then outline the method of research before presenting the findings and analysis, which we discuss. We present a revised research framework before drawing conclusions and implications for managers and future research. 


\section{LEARNING IN IJVs}

Taking a firm-level and especially a IJV partner level perspective, IJV research has mainly focused on the resource bases and skills of the partners, and on structural factors between them such as their trust and commitment, and the contractual formats they use (e.g. Luo, Shenkar, \& Nyaw, 1998). It has also highlighted the importance of learning, seeing it as an IJV partner driven activity in which knowledge is held by partners, who institute processes to get knowledge and learning into and from the IJVs and where the IJVs, who also institute processes to get knowledge from the IJV partners (Beamish \& Berdrow, 2003). The amount of knowledge available for transfer within IJVs therefore initially depends on the IJV partner's prior knowledge and experience (e.g. Tsai, 2001), where the more diverse the sources, the greater the opportunities for learning (Huber, 1991).

Research also shows that an IJV's competitive advantage depends on its absorptive capacity (Mahnke, Pedersen \& Venzin, 2005; Minbaeva, 2005; Tsai, 2001). This learning capability to acquire, assimilate and exploit new knowledge from the partnership (Gupta \& Govindarajan, 2000; Szulanski, 1996; Yao, Yang, Fisher, Ma \& Fang, 2013) and to innovate with the creation of new knowledge (Kim, 1998) is critical for knowledge acquisition in international settings (Cohen \& Levinthal, 1990; Yao et al., 2013). When IJVs are formed as part of one partner's internationalization strategy, for example, this strategic advantage would be sought by combining one firm's firm and location specific advantages with another's, with one of the firms having location advantages in particular territories (Rugman \& Verbeke, 2001). Being able to structuralize learning and knowledge processes is a strategic source of international competitive advantage for IJVs (Foss et al., 2010; Kandemir \& Hult, 2005).

The process of integrating knowledge and learning across national boundaries, and between individuals from different backgrounds, however, raises major challenges within IJVs (Luo, 2009; Meschi \& Riccio, 2008; Westney, 2001). Learning between partners from different national contexts is inhibited by different ways of social interaction and different understandings (Morgan \& Kristensen, 2006; Pak et al., 2009). If the partners have different organizational cultures, developing absorptive capacity is especially complex (Daghfous, 2004; Nti \& Kumar, 2000; Tsai, 2001). While more parties and more diverse partners can present more learning potential, it can also inhibit inter-partner cooperation and IJVs performance (Gong et al., 2007). 
The role of IJV managers where the partners differ greatly is critical; they need to achieve high intensity of learning effort (Park \& Ghauri, 2011). Organizational learning research has noted the importance of IJV managers' capacity to absorb new knowledge, and that internationalizing firms are not restricted to experiential learning emphasized in international business research (Johanson \& Vahlne, 1977, 1990) but can also use vicarious learning, congenital learning, grafting, searching and noticing for their learning and knowledge acquisition (Cohen \& Levinthal, 1990; De Prijcker, Manigart, Wright \& De Maeseneire, 2012; Huber, 1991). IJV managers need to construct specific and particular organizational routines and processes to facilitate learning for their businesses (Bhagat, Kedia, Harveston, \& Triandis, 2002). As yet, however, research is yet to identify what these might be.

The learning processes involved in IJVs involve many different levels. These range from the outset learning objectives on the party of the IJV partners, to the learning structures and processes that they institute, to the processes that the partners' and the IJV's managers follow, to the specific activities and orientations of those managers as individuals. Little IJV research has been undertaken at a management process or individual manager level, so the individual managers' agency in this process, and the processes of learning in which they engage remain unclear.

Interpreting overall developments where its constituent behaviors take place at multiple levels is a fundamental problem in business research (Nicolini, 2012), but one that has been addressed through the concept of "microfoundations". Microfoundations represent explanatory mechanisms located at the level of the individual, individual actions and processes, and interactions between those and other mechanisms concerning phenomena that can be located at a higher level. The research question of this study concerns the "microlevel" of individual actions, and interactions that help IJV firm-level learning. Contention and debate concerning this approach has been provoked, inter alias, by the confliction of levels of analysis intrinsic to this approach (see, for example, Jepperson \& Meyer, 2011; Winter, 2011; Pentland, 2011). Some resolution of many of these issues has been offered by Nicolini (2012) who proposes that attention to microfoundations not be undertaken in isolation from analysis at macro or intermediate levels. This study adopts a critical realist position and adopts this approach to gain a fuller and more comprehensive understanding in a poorly researched area.

For IJVs created for internationalization of one partner, therefore, the macro-level outcome of firm specific advantage (FSA) transfer might reflect macro-level explicators of, for example, the partner's extant FSAs and structures. Understanding the learning processes, 
however, is incomplete without examination and consideration of the micro-level actions and processes of the individual managers involved (the focus of this study), notwithstanding that these take place within a macro structure of the partners' organizations and the IJV structure that may shape or constrain their behavior. Felin et al. (2012) propose a framework that goes some way to reconciling these tensions, and this is now examined in the context of IJV management.

\section{MICROFOUNDATIONS FOR IJV LEARNING}

Felin, Foss, Heimeriks and Madsen (2012) categorize microfoundations lying within individuals, within social processes and within structures, and also between each of these categories (Figure 1). Different processes have been recognized to help learning within organizations (Pentland, Feldman, Becker \& Liu, 2012), but we also know that effective absorptive capacity building depends on the capacity of the individuals concerned, and on the overlap between individuals' knowledge sets (Cohen \& Levinthal, 1990; Foss et al., 2010).

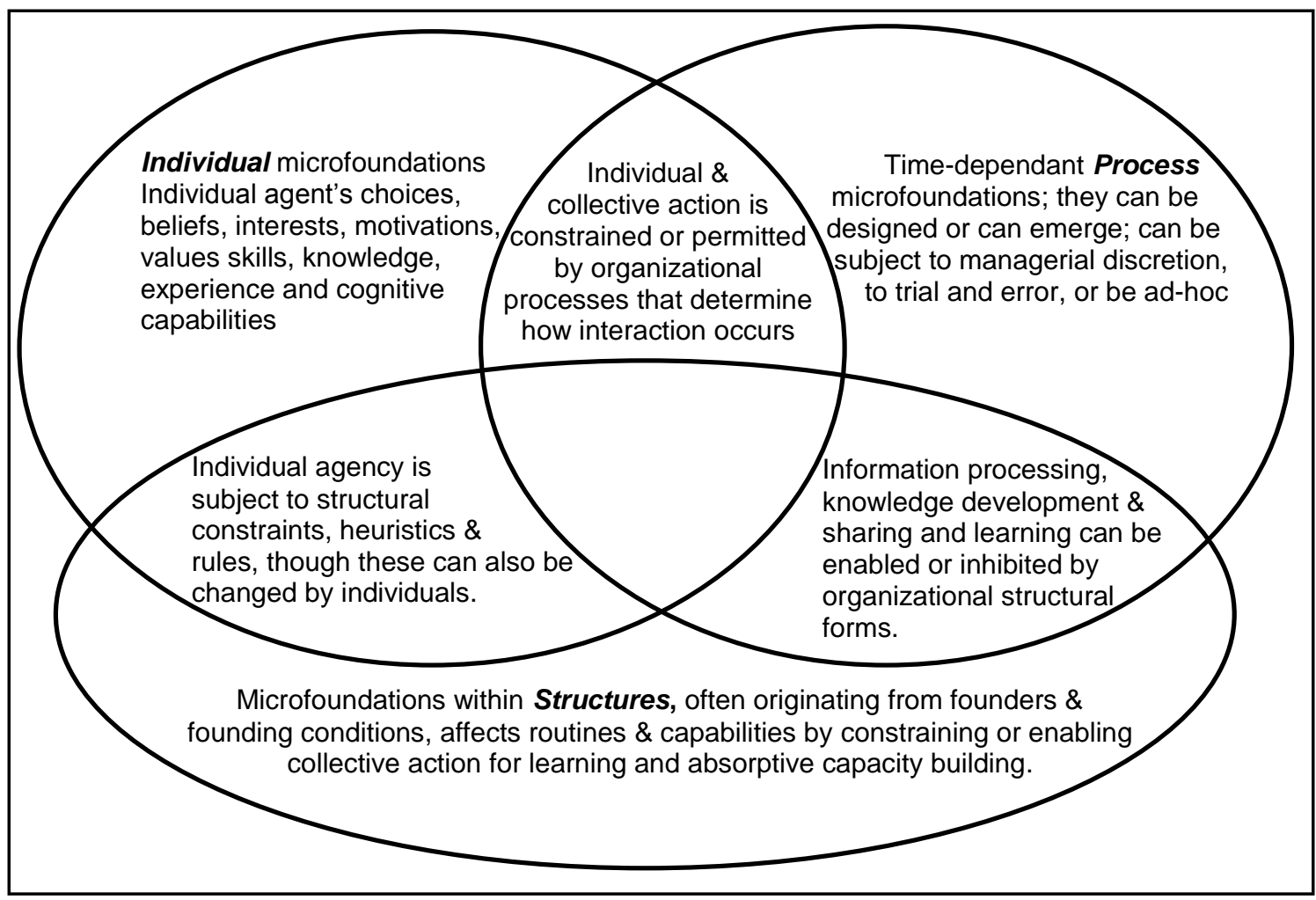

Figure 1: Microfoundations of organizational learning (derived from Felin et al., 2012) 
Managers as individuals influence the behavior and evolution of organizations (e.g. Groysberg \& Lee, 2009); their actions interactions are a microfoundation for learning (Foss, Laursen \& Pedersen, 2011). It is their managerial operationalization of organizational routines and capabilities that can generate and maintain competitive advantage (Felin et al., 2012). We can expect these three micro-components to have to interact if learning and organizational capacity building is to take place at an organizational or IJV level (Stinchcombe, 1991), as is represented in Figure 1. In the proceeding sections, each of these will be examined in turn.

\subsection{Individual level microfoundations of IJV learning}

For firms to 'learn to learn', different levels of learning are required; individuals within them need a new type of learning, which is then compounded into a new collective capacity (Anand \& Khanna, 2000). Here we employ Argyris and Schön's (1978, 1996) notion of learning levels, a concept that was conceptualized and developed as a way of understanding individual learning, but which has been widely applied to the understanding of organizational learning. 'Single-order', 'single-loop' or lower level learning has been distinguished from 'double-order', 'double-loop' or higher level learning (Argyris \& Schön 1978, 1996; Bateson, 1979; Fiol \& Lyles, 1985).

Single-loop learning involves the detection of and correction of errors, an adaptive process that is restricted to the subject of that error, the 'governing variables' (Argyris, 1976, 1977; Argyris \& Schön, 1978). Double-loop learning takes place not only as a result of the detection of errors, but also as a result of questioning as to the governing variables themselves. This not only generates adaptation, but also a capability of having adaptability. In double-loop learning, a continuous process of experimentation and feedback guides the governing variables themselves and allows firms to undertake radical change, for example by changing the way in which strategies are formed, by solving new problems, and by taking advantage of new opportunities (Argyris, 1976, 1977; Argyris \& Schön, 1978). Double-loop learning is needed for sustainability in fast changing environments which require continuous experimentation, feedback and change (Hedberg, Nystrom \& Starbuck, 1976).

International business research has emphasized the importance of knowledge transfer in international business environments, such as within MNEs (Gupta \& Govindarajan, 2000; Mahnke et al., 2005; Minbaeva, 2005; Tsai, 2001), where a key competitive advantage arises from an international firm's capability to create and transfer knowledge (Kogut \& Zander, 1993). The capacity for firms to adapt and change and to be innovative by being sufficiently 
adept at finding, acquiring and incorporating new knowledge has been incorporated into the organizational notion of absorptive capacity (Cohen \& Levinthal, 1990; Tsai, 2001). Absorptive capacity is especially critical for JVs constructed as the result of a learning need because it is this that allows the JV to acquire and exploit the new knowledge that is available (Cohen \& Levinthal, 1989).

The way that the firms work with one another will determine what, and how much each partner will learn from the partnership (Glaister et al., 2003); businesses and IJVs can differ in how well they can usefully realize and use their absorptive capacity (Jansen, Van Den Bosch \& Volberda, 2005; Zahra \& George, 2002), depending on the way in which the managers involved work with one another (Glaister et al., 2003) and on teacher's and student's capacity for knowledge transfer (Park, 2011). Studies have identified a number of elements that can contribute to absorptive capacity within international settings.

First, the more compatible the knowledge being acquired and transferred between firms, the more effective the absorptive capacity (Lane \& Lubatkin, 1998). Second, international partners are more likely to learn from each other when they share similar business backgrounds, so absorptive capacity is enhanced by close business relatedness (Park \& Ghauri, 2011). Third, managers' intensity of effort in learning, reflected in strengthening interaction amongst individuals, is critical in building sufficient absorptive capacity for international development at the organizational level (Kim, 1998; Liu, Ghauri, \& Sinkovics, 2010; Park \& Ghauri, 2011). Fourth, the managers' prior knowledge base, its form, and where and how it is located can help (Simon, 1991). Different managers and different parts of firms may have different knowledge and abilities, and also different abilities for learning from others. For IJVs, therefore, we can interpret absorptive capacity as a path-dependent construct that builds on the extent form and location of the managers' prior knowledge, and is driven by their intensity of effort in acquiring new knowledge (Cohen \& Levinthal, 1990; Lane et al., 2001; Linyanage \& Barnard, 2003).

\subsection{Processes and interaction microfoundations of IJV learning}

Since Johanson and Valhne's $(1977,1990)$ early contributions to our understanding of the internationalization process, the importance of learning in that process has been well appreciated, and organizational research has also recognized the ability to learn within organizations potentially to be the most critical intangible asset that a firm can have (Child \& Faulkner, 1998: 287). Internationalization process research has especially emphasized the 
importance of experience in that learning; Johanson and Vahlne's (1977, 1990, 2006) internationalization process model, based on Johanson and Wiedersheim-Paul's (1975) work and behavioral theories of the firm, focuses on learning by doing, whereby firms increase their level of know-how in foreign markets before expanding into them. Under their dynamic evolutionary internationalization process model, experienced knowledge reduces apparent uncertainty in non-domestic markets and helps firms to distinguish and create opportunities in those markets (Forsgren, 2002; Johanson \& Vahlne, 1977, 1990, 2006).

As Steen and Liesch (2007) have argued, however, internationalization process theory holds the separation of objective from experiential knowledge as a conceptual underpinning, one that is rooted within Penrose's (1959) theory of the growth of the firm. It is because it assumes international market knowledge to be subjective and based mainly on experience gained accumulatively from market activity that it concludes that that internationalization is a gradual, incremental process (Johanson \& Vahlne, 1977, 1990; Steen \& Liesch, 2007). Further, internationalization process research has extensively examined the process of internationalization, has observed the importance of learning, and has catalogued the content of knowledge that is needed, but it has paid little attention to how they actually learn it, and has continued to assume that the process of knowledge acquisition and learning is experiential (Johanson \& Vahlne, 1977, 1990, 2006).

Here we are concerned with IJVs constructed specifically to achieve successful market entry with each partner having their own different, but potentially important, knowledge. The learning processes between the partners are clearly critical in these cases and different methods of knowledge acquisition and organizational learning might be anticipated. International business research, however, has focused on the content of knowledge transferred between the parties, rather than on how IJVs might acquire, learn and exploit it.

The process of learning has been examined extensively within organizational learning and development research (Dewey, 1987; Kolb, 1984; Kolb \& Kolb, 2009), and internationalization studies published in this journal have begun to looked to organizational learning theory to inform their research (e.g. Fletcher \& Harris, 2012). Experiential learning only occurs in the course of solving problems or in current activities (Arrow, 1962), because it requires personal observation, imitation, and practice or training which cannot be codified in written format and cannot be stated explicitly (Nonaka, 1994). Kolb (1984) argues that emphasis on the involvement of experience in the learning process differentiates experiential from other cognitive learning, making it "a holistic process of adaptation to the world" (Kolb, 
1984: 31). Here, learning is "conceived as a process" that involves the continued recreation of experience, and is not seen in terms of outcomes (Dewey, 1987: 79).

Learning processes have also been explored in organizational theory and strategic management research (Huber, 1991). Huber's (1991) framework has been widely employed in organizational research and has recently been employed to understand the learning processes of internationalizing small and medium-sized enterprises (SMEs) (Fletcher \& Harris, 2012). It recognizes the importance of the experiential learning emphasized in internationalization research: congenital learning is inherited knowledge from first-hand experience and determines what a firm explores or looks for, what it experiences, and how it interprets what it comes across (Huber, 1991). The amount that organizations, including IJVs can learn depends on their stock of congenital knowledge, the intensity of their learning effort, and their absorptive capacity which depends on their managers' experience, such as in operating internationally (Oviatt \& McDougall, 2005).

Huber (1991) also recognizes other internal and external learning processes: vicarious learning, grafting, searching and noticing that are likely to be important in IJV contexts with their need to learn strategies, practices and technologies from other organizations (Sahal, 1982). Vicarious learning, which involves imitating or copying practices, can be from competitors, as Porter (1980) suggests, or can be from partner firms (Eells \& Nehemiks, 1984). Grafting is a way of acquiring knowledge from external organizations (including partners) by bringing in individuals who hold new knowledge. This is frequently quicker than acquiring the knowledge experientially, and the knowledge can be acquired more comprehensively than through vicarious learning (Huber, 1991), so is used most when there is a greater need to assimilate knowledge (Drucker, 1988), as in IJVs (Lyles, 1988). Searching and noticing knowledge, internally or externally, takes place in the everyday process of management (Huber, 1991).

While Huber's (1991) work focuses on the different processes of learning rather than on its results, we know that firms can exploit knowledge and extend organizational competence through more effective utilization of skills and processes (Glaister et al., 2003). These different processes of learning can substitute for one another to some extent, but each possesses characteristics that favor application in particular situations (Huber, 1991). 


\subsection{Microfoundations for organizational learning at the structural level}

Different forms of organizational and governance structure set the context for enabling or constraining interactions and activities in learning within an organization (Felin et al., 2012:

\footnotetext{
Structures, whether at the organizational level or within an organization, specify the conditions that enable and constrain individual and collective action and establish the context for interactions within an organization. While structures may constrain behavior, they also enable efficient information processing, knowledge development and sharing, coordination and integration, and more generally, collective action. [p. 14]
}

How organizations are structured determines how decisions are made by individuals and groups, and the processes pursued within the business; managers' behavioral choices will reflect organizational and governance constraints (Ingram \& Clay, 2000). The process of integrating, disseminating and sharing knowledge differs within and between organizations in how much it is done and how it is done, in other words, its 'knowledge governance' (Foss et al., 2010; Grandori, 1997; Michailova \& Foss, 2009).

Managers' knowledge sources and their scope to gain and exploit knowledge are governed by the organizational structure in which they work (Abell, Felin \& Foss, 2008; Foss et al., 2011) and by the governance mechanisms in place (Gottschalg \& Zollo, 2007). Structure can therefore also facilitate or inhibit learning; the autonomy proffered by flat structures, for example, is thought to help learning, but also to create gaps that can inhibit knowledge sharing (Foss, 2003). Within IJVs, this is determined by the partners' structural settings, and the process of exchange between them influences how the IJV develops (Gong, Shenkar, Luo \& Nyaw, 2007). Although IJVs can be a means for managers to promote their organizational learning by offering the opportunity to access skills and knowledge from partners (Beamish \& Berdrow, 2003; Tsang, 2002), there are distinctive structural barriers to organizational learning in IJVs because they are not the same company. The structural formations of IJVs therefore need to be considered separately from those of other multinational firms or because they are positioned at the conjuncture of two or more independent organizations (Gong et al., 2007). 


\section{METHODS}

This study sought to identify the details of the learning processes in the context of IJVs formed as part of an internationalization strategy and explain the reasons for the learning choices that IJV managers were making. This suggested an exploratory study in one or more IJVs that were actually undertaking some learning to gain access to those individuals who were doing that learning over a period of time, for the purpose of inductive theory building (Eisenhardt \& Graebner, 2007; Ghauri \& Grønhaug, 2010; Yin, 2009) not driven by a priori expectations framed in one conceptual standpoint or another.

We chose to undertake a single case study that would enable us to examine the individuals involved in the learning process sufficiently to allow us to make theoretical generalizations (Eisenhardt \& Graebner, 2007). The focus here is in the authenticity of data interpretation rather than reliability (Ghauri, 2004). For this, one of key elements in the research design is the employment of multiple sources of interviewees and other data in the data collection (Miles, 1979). Cases for describing phenomena in-depth are chosen with theoretical sampling logic for their potential to show theoretical reasoning (Siggelkow, 2007), and in a single-case study, this process is critical, with selection depending on the uniqueness of a specified case in relation to existing theory. As Ghauri and Grønhaug (2010) note:

\footnotetext{
Single case is appropriate when a particular case is a critical case and we want to use it for testing an established theory. It is a critical case because it meets all the conditions necessary to confirm, challenge or extend the theory. Another situation is when a single case is an extreme or a unique case. Finally, a single case design is appropriate when a case is revelatory. [p. 114]
}

In the following sections we summarize the four phases of the research procedure, beginning with the criteria for sampling the case, and the steps that were performed to establish data equivalence (Sinkovics, Penz \& Ghauri, 2005).

\section{Phase 1: Identification and theoretical sampling of a case IJV.}

Secondary data such as company profiles, interim reports and financial data, was reviewed to theoretically sample a large single case IJV, Homeplus (Eisenhardt \& Graebner, 2007). Homeplus was purposefully selected as an exemplary successful IJV with the UK retailer, Tesco and the Korean electronics firm, Samsung as partners (Ghauri \& Grønhaug, 2010). As our focus is on specific learning processes within IJVs, we sought a large IJV with large partners from very different cultures, where the opportunities for learning would be great, but the complexities in undertaking that learning may also be expected to be substantial (Ghauri \& Grønhaug, 2010). 
Our context is therefore a retail IJV within Korea. Homeplus currently ranks second in Korea after E-Mart, a domestic competitor. Homeplus represents Tesco's largest international business outside the UK with revenue of $\$ 8$ billion. The scale of this achievement has been noted within the retail industry, because Korea's unique culture, strong nationalism and ethnic homogeneity generates a hostile environment even for the strongest retailers, most of whom, including Wal-Mart and Carrefour, have withdrawn from the territory (Kim, 2006). Homeplus's success reflects the combination of the complementary resources resident within its partners that were planned from the outset, and provided the basis for the purposeful selection of this case. Successful internationalization for Tesco required that Homeplus managers, all Korean and mainly Samsung trained, to absorb retail management capability from the Tesco organization, by learning best retail practice from Tesco managers and experts, to absorb that knowledge, and to apply it within the Korean retail context that they already knew well. It is therefore that learning process, and its microfoundations, that are the focus of this study.

In order to uncover the managerial factors that generated the IJVs' success it was important to gain the cooperation of those that were driving it within the IJV, and in partners, and this was secured. The research design also paid attention to achieve high levels of data equivalence throughout the research phases in order to ensure reliability and validity and to avoid possible bias in findings and theoretical implications (Ghauri \& Grønhaug, 2010; Sinkovics, Penz \& Ghauri, 2008).

\section{Phase 2: Interview guide development.}

To collect deep empirical data on phenomenon, such as IJVs, that are 'episodic and infrequent' (Eisenhardt \& Graebner, 2007: 28), and the perspective of those involved in them, interviews are the most useful method (Yin, 2009). This study used a precise interview guide developed using Lofland and Lofland (1995) and Kvale's (1996) techniques of formulating questions in diverse contexts.

The questions followed a logical sequence that would yield narrative continuity and cohesion. A precise interview guide structure achieved consistency of the interview procedure, which was essential to lead dialogue to applicable issues as well as to maintain the highest possible comparable data from each interview to ensure functional and conceptual equivalence (Harris, 2000; Sinkovics et al., 2005). Nearly all the questions were asked in similar phrasing to all interviewees for consistency in collection of data, and the language used was simple with business terminologies only used where necessary (Harris, 2000; 
Remenyi, Williams, Money \& Swartz, 1998). To avert problems of cueing interviewees' answers (Perry, 1998), the interview guide allocates some degree of flexibility in answering questions in non-directive way as possible, helped to extract more detailed answers, and allowed refinement of the questions while interviewing (Kvale, 1996; Harris, 2000; Yin, 2009). These features and the data-data triangulation processes averted the danger of confirmatory evidence bias that may arise from previous theoretical development in organizational learning (Sharpe, 2004; Yin, 2009).

The interview guide was written in English before being translated into Korean, and then both English and Korean interview guides were reviewed by two professional Korean linguists for clearness to establish translation equivalence (Sinkovics et al., 2005). Five different interview guide versions were prepared to suit the different groups of interviewees.

\section{Phase 3: Semi-structured interviews.}

The large numbers of departments, sections and units in Homeplus meant that selecting appropriate interviewees to address the research questions was critical (Ghauri \& Grønhaug, 2010). Top and middle level managers from different departments in Homeplus, Tesco and Samsung in Korea and industry experts provided 60 to 180 minute interviews in 2011 and 2012. These included global sourcing, strategic management, marketing, regional deployment and supply chain managers and vice presidents involved in developing Homeplus, and managers with relationships with Tesco headquarters and its other international operations.

As these were top and middle managers there was a danger of upper-echelon bias (Hambrick \& Mason, 1984; Pudelko \& Harzing, 2007), so triangulation data was collected from other levels at each firm, as well as other related partners, industry bodies and academics. There were, overall, five groups of interviewees: MNE managers within the IJV, local partner managers within the IJV, MNE managers at HQ, local partner managers in the local HQ, and other related partners and academics. Most were conducted 'on site' in Korea, in Korean and in English. The equivalence of the phenomena and constructs had to be ascertained because of the different nationalities of the interviewees, who had their own standards of cultural behavior and psychological approaches (Ghauri \& Grønhaug, 2010; Sinkovics et al., 2005). The research aims were explained and an assurance of confidentiality was given to each interviewee. Anonymity was achieved by assigning numbers to replace names. Interviews were recorded and transcribed and after each interview, a note list comprising key points was composed to allow inductive development of new themes. A 
sample of the interviews were repeated for further clarification on specific issues and were followed-up by e-mails and telephone calls to confirm the data (Ghauri \& Grønhaug, 2010).

There are many challenges in the use of language in cross-cultural international research (Usunier, 1998). Here, except for some expatriate Tesco managers who were interviewed in English, most of the interviewees and the primary researcher were Korean, who used their native Korean language (Marschan-Piekkari \& Welch, 2004). Korean language transcripts were translated into English presented translation error risks including distortion of the data and losses of nuance, that were addressed in four ways. First, translation equivalence was obtained through back-translation of a sample of the transcripts to identify any differences in meaning of words, for example in the definitions of 'learning' and 'competency' (Sinkovics et al., 2005). Second, in areas where there are uncertain terms or meanings, undirected discussion around these was undertaken within the interviews. Third, to ensure as far as possible that the precise meaning intended was derived from the transcripts on translation, the translations were also double-checked by professional linguists. Fourth, follow-up interviews were conducted for further clarification and discussion when necessary.

The research design established trustworthiness and validity in its findings by establishing credibility through triangulation, transferability by using thick descriptions, dependability with an audit trail of all documentation and the use of Nvivo7 computer assisted qualitative data analysis software to systematically manage the data and standardize the classification of codes and inter-linkages, and confirmability by independent and neutral researchers using an interview guide designed to be unbiased (Sinkovics et al., 2008; Yin, 2009). Multiple sources of archival data were employed to triangulate the data which included corporate internal materials, interim reports and media data sources and a number of industry conferences that were also attended included discussion of the topics addressed.

\section{Phase 4: Qualitative data analysis, evaluation and re-evaluation}

The process of analysis began shortly after the first interview, to enable the research problem and new questions to be recreated with evolving theoretical developments as new data accrued (Ghauri, 2004; Ghauri \& Grønhaug, 2010; Miles \& Huberman, 1994). This early approach to analyzing data enabled the researchers to minimize collection and analysis of irrelevant or superfluous data (Ghauri, 2004). Inductive data coding through content analysis of transcript data, initially into categories identified from the organizational learning and internationalization process literature for data-theory triangulation (Yin, 1993). Strauss 
and Corbin's (1998) microanalysis approach of comprehensive line-by-line data analysis then identified associations amongst categories, which formed new codes through a process of conceptualizing, reducing and elaborating of data. This process, similar to formal analytic modeling, minimizes concerns regarding the subjectivity of the data, and results in a more accurate inductive theory building process from case data (Eisenhardt \& Graebner, 2007; Yin, 2009). In this way, analysis was iterative, and allowed continuous triangulation between theory and data (Yin, 2009).

\title{
5. ANALYSIS: THE IJV STRUCTURE
}

While previous knowledge acquisition and learning IJV research, reflected in Figure 1, indicates that knowledge would be acquired from the partners, we found other sources of knowledge to play a critical role. IJV research has paid little attention to the role and interaction of the partners' other subsidiaries with the IJV, but we found that relationships with Tesco's other international subsidiaries were critical in sustaining Homeplus, with considerable passing of knowledge from these to Homeplus. These contacts were sourced and driven directly by the Homeplus management themselves, without the suggestion or involvement of the partners' HQ at all. Homeplus managers regularly visited and worked closely with managers in Tesco's other international subsidiaries:

\footnotetext{
With deployment managers, I have weekly conference calls. Every six months, we (Homeplus) have shared learning events by region and every six months I would go somewhere in Asia and we meet and we share our approach whether we are on track or not. [H2]
}

\begin{abstract}
When sharing our (Homeplus) learning with Tesco's other international operations, we use tele- and callconferencing with normally five other countries simultaneously. These include Tesco HQ and operations in emerging markets such as Thailand. Learning and best practices developed in some international operations are then transferred to others, such as in Thailand, which are still in the early stages of development. For examples, in rolling out Telecom business in Tesco Thailand we transferred the skills and knowledge we successfully developed in Korea. [I2]
\end{abstract}

We (Homeplus) have regional commercial directors' meetings, about once in every six months. And I have been asked to coach for the members of countries and I have shared my experiences with the UK management, for example, on bakery model and on meats. [H1]

Cooperative behaviors between units and managers were important, as Österberg (2004) suggests, in which Tesco's investment in Homeplus boosted knowledge sharing actives within Tesco's other operations:

The IT system within the IJV in Korea is very advanced and in 2003 Tesco HQ invested around 20 billion Won (\$18 million) in constructing a global IT hub project by Homeplus IT management in Korea. [I9]

Overall, we see processes of shared learning with the partners' other subsidiaries globally to be critical:

We (Homeplus) will share knowledge and agree best practice and then functional experts will make their decision to build into operating models. [...] The operating model is not Tesco UK driven. It is learning from all our 14 international countries together. I want to make it clear that it is not about the UK model. The UK 
is our central operation, they have information from all the 14 countries, and they claim the best practice. [H2]

This shared learning, driven mainly by the IJV managers themselves, passed from Homeplus outwards. When Homeplus directly transferred systems from Tesco HQ, Homeplus usually had to modify and further them to fit into Korean market setting. The manuals and materials Homeplus produced were then often useful for other Tesco's international operations, especially in emerging markets. This shared learning processes not only enhanced the IJV's practice but also helped improve the partner's other international operations systems.

In becoming an important source of learning elsewhere, as Lyles and Salk (1996) found, the size of the operation was important. Homeplus was Tesco's largest international operating business with 2011 revenue of $\$ 8$ billion out of Tesco's total Asia revenue of $\$ 16$ billion (Tesco, 2011). The outcome was shared learning that was also useful for Tesco HQ, so the IJV management voluntarily produced reports and case studies for proactive knowledge sharing:

\footnotetext{
In terms of case studies I am just keeping the records for the business, what I am doing with those records is sharing them with my colleagues in other countries so that we can take same approach or adapt accordingly. [H2]

We (Homeplus) have IT capabilities that we have developed here and searching capabilities that we transfer to other countries, especially building multi-story stores. [H1]

Learning best practice should be done cost-effectively. The best way to learn best practice is usually done by way of a regular call conference, sharing case studies etc. [I2]
}

From a strategic perspective, firms look for partners with different capabilities and skills to gain resource synergies as partners (Luo, 1998). Previous research has indicated that business relatedness and shared business backgrounds help partners to learn from each other, to exploit the relevant knowledge, and to develop absorptive capacity (Lane \& Lubatkin, 1998; Park \& Ghauri, 2011). IJV experiences show that partnerships between firms of different backgrounds often fail due to the difficulties of learning between partners (Buckley \& Casson, 1988; Park \& Russo, 1996), for example because of differences in organizational culture (Anh, Baughn, Hang, \& Neupert, 2006). Business relatedness between partners helps them to learn from each other (Park \& Ghauri, 2011).

Homeplus, however, was created because the partners were from very different backgrounds, with different national and industrial cultures, Samsung from manufacturing and Tesco from retail. Tesco and Samsung could not employ people, at least at HQ, who were sufficiently close to the activity of the IJV to be useful sources of learning; the industrial and cultural differences were too great. But because Homeplus and its partners shared a 
similar vision and goals (Newburry, Zeira \& Yeheskel, 2003), Tesco and Samsung were able to give autonomy to Homeplus managers to seek out people to learn from, and they chose the partners (mainly other Tesco subsidiaries, such as Tesco China or Tesco Thailand) and consultants, both sources with backgrounds most related to their activity:

\footnotetext{
I would not say that Tesco is driving most of the new changes here (Homeplus) in Korea. We both drive new changes and initiatives together. In a way Tesco is acting as our supporter as we work towards common goals. The process is definitely an interactive one with both partners driving together as one. [I2]

Tesco learnt enormously from us at least in their international operations. As we are the largest and most successful Tesco international operation; vice-presidents who worked here have then been sent to CEO roles in other operations such as in Tesco Thailand, Malaysia, China and Poland. Those vice-presidents who worked in Korea for few years are taking all the necessary learning and skills that they learnt here so that they can apply similar success to other countries. For example, store concepts and culture centers for extended education. [I6]
}

This case contrasts clearly with Park and Ghauri's (2011) study of closely related technology firms, who could more readily develop their absorptive capacity by learning from their partners, from whom the IJV managers could more readily access relevant knowledge. We would therefore propose that IJV managers may require more autonomy when their partners are dissimilar than when their businesses are closely related to one another.

Expatriates from the UK who work in Korea met informally regularly and exchanged personal experiences and work related information. They also contacted expatriates working in Tesco's operations in China, Thailand and Japan:

\footnotetext{
I sometimes act as a communication channel. I speak to the Tesco CEO of China regularly. Sometimes, the Tesco CEO of China if they want to interview a candidate for the certain type of job, then I interview them. [...] I meet regularly with other expatriates I met abroad, usually informally. I maintain contacts from my roles in Japan, China and so on. [H1]

(We have) about four or five Tesco UK expatriates (for training at the moment). (We arrange) short visits (for expatriates working in Tesco UK and Tesco's other operations). Usually shop visits. In stores and showing them (our store formats and products). [H1]
}

Before the UK expatriates are sent to their respective international roles, they usually acquire knowledge and information from expatriates from those respective countries. Korean expatriates who work in Tesco HQ also learn and acquire knowledge from the UK expatriates in Korea:

Before I came here (Korea), when I was asked to take the role, I agreed to meet three or four Korean teams working in Tesco UK. I spent quite a bit of times with them. [...] It has been very successful but I think it is also well planned. [H2]

Unexpectedly, we found that the learning from the IJV managers' own sources was also important for further learning within the JV as well. Most of the managers considered it important that they were themselves actors in the knowledge acquisition and exploitation process, regardless of their management levels and departments. Managers actively sought, shared and transferred knowledge, thus absorbing the knowledge they needed. 


\section{ANALYSIS: THE MANAGERS AS INDIVIDUALS}

The autonomy of the managers meant that their prior knowledge was critical for building and sustaining the IJV relationship for both partners prior to and during the IJV. Internationalization experience had taught Tesco that having partners that shared the same prior knowledge or types of knowledge would lead to IJV failure and the two partners sought partners with different prior knowledge and capabilities, in areas that they could not readily learn or acquire. A firm's prior knowledge is known to be crucial for internationalizing firms to appreciate the need for new learning, and for achieving appropriate knowledge transfer (Autio, Sapienza \& Almeida, 2000; Cohen \& Levinthal, 1990). Organizations are able to learn best when new knowledge is linked to the prior knowledge base and when there is some focus on processing new external knowledge (Autio et al., 2000; Cohen \& Levinthal, 1990; Zahra \& George, 2002). Tesco's distinctive knowledge of best practice in retail projects was derived from more than 90 years of experience in the UK, as well as from international operations since 1995. Samsung had local market and business knowledge developed in a wide range of industries for over 70 years in Korea:

\footnotetext{
The combination of Tesco's retailing skills, the Korean business skills and knowledge that the local team brought, and the rapidly developing economy made it the right time for the development. [H1]

Whilst Tesco HQ possessed a stock of cumulated extensive retail knowledge from their internationalization experience offline, Homeplus made it viable via online networks. Initially, Homeplus developed an elearning system suggesting enhanced virtual knowledge sharing within Tesco's network. [I9]

The Tesco HQ Global Sourcing Team is not familiar with Korean market and sometimes they cannot assess our market well. When they suggest some new product ranges for us to sell here (Korea), these are sometimes not appropriate for us. The CEOs (Homeplus) often say that Koreans need to be in charge in order to fully understand the culture and local market. If we manage our company as Carrefour or Wal-Mart did in Korea with foreign expatriates being in charge, we would not be in the market where we are now. So in terms of global sourcing, we are developing our own range here. [I1]
}

The case managers emphasized the important role of the partners' prior knowledge for sustaining the IJV relationship and making it work. It was important for each partner to contribute its own distinctive knowledge to the IJV, in such a way that the other partner could completely rely on it and trust it in that area of distinctive knowledge. The IJV's overall manager refers to Homeplus as a hybrid:

\footnotetext{
There was a lot of knowledge sharing but it went in strange ways. So basically we got a team of Koreans, very Korean guys who did not know very much about retailing. What they got was probably a maximum of four or five UK expatriates who helped to develop capabilities and implemented the Tesco way and the Tesco system. So what you had was a strange hybrid where general managers here (Korea) know about Korea but not about retailing. Then you had retailing professionals who have been doing it for longer and who have come here and developed the capabilities, so that is the way that the knowledge has been shared. [H1]
}

Local market knowledge is closely linked to cultural issues that are hard to acquire or learn quickly; adapting to new culturally diverse markets can be a subtle process. 
Respondents confirmed the difficulty of learning this knowledge and cultural background, even if there is a lot of time:

\begin{abstract}
The main thing I have learnt is it is hard to work in a culture that is very different from your own. We have four expatriates at the moment. All foreigners feel working in Korea is difficult because of the culture. Korea is a very different culture to me. [H1]

I think Tesco UK realized by the time they were looking to internationalize into Korea that they should not even attempt to learn a culture which is so different to their own. [S2]
\end{abstract}

Here, Tesco wanted its partner to deal with these cultural issues, reflecting the structural arrangement in which each partner relied on their partner to do the work where they had distinctive knowledge. The partners did not set out to transfer their own prior knowledge into the IJV, or themselves to learn distinctive knowledge, so the process of learning new knowledge was minimized. Homeplus managers were largely on their own, and because they knew that they had to learn if they were to succeed, their intensity of learning effort was high. As Park and Ghauri (2011) identified, the intensity of effort is an important indicator for developing an effective absorptive capacity:

\footnotetext{
Tesco almost assigned Homeplus to us (Samsung). Tesco's main guideline was to pursue a localization strategy in Korea which is their basic strategy (when they go abroad). Tesco learnt and self-reflected from their failed operations elsewhere for instance, Tesco's failure in Ireland, despite the fact that they speak the same language. They learnt that when they pursue a standardization strategy by transferring their modern form of retailing knowledge directly into foreign markets, it would not suit the need of local customers and industry structures. After systematic review and analysis, Tesco realized the localization strategy was key in international operations. [...] This strategy is in their manual now. [E2]

We (Tesco) don't tend to have a prejudicial mindset (towards developing economies) as a group of companies. The UK is a lot bigger than us and Japan is much smaller than us. We have the CEO as a group function but mainly its countries working on their own and sharing their knowledge. The cross model is the most effective ways of learning between IJVs. [H1]
}

As a result, the IJV managers' prior knowledge facilitated cross-fertilization, integration, and combination of knowledge and learning with prior bodies of knowledge. This further increased the speed of learning and helped its application in a way focused on the IJV's needs, generating a double-loop learning process within the IJV itself:

I have a management consulting background. My prior knowledge of analytical skills really helped me to define the key problems we were having much faster than my team did. [...] I did not have to learn how to use and apply familiar frameworks or templates. My previous knowledge was easily transferable to the retail setting. [I2]

We see Homeplus managers using their own relationships and sources in order to gain knowledge that they needed in ways that did not involve either the partnership or its partners. Networks were important here. Some managers used the consultants who had originally advised Samsung on its retail expansion, and other managers, who had had a management consulting background, used their own network to find the appropriate consultants for their specific projects. Some of managers were successfully applied it to commercial ends. Managers used, for example, their own networks from their prior experiences to organize 
training and workshops, especially when seeking and pursuing new business opportunities such as in telecoms, insurance and credit card services:

I was asked to organize training programs and workshops. I had to use my own networks from previous work to find suitable speakers in consulting and develop a program with them. [I2]

Prior knowledge and organizational routines have also been found to inhibit learning as well, if they are difficult, expensive or time consuming to modify to the requirements of the new context (Teece \& Pisano, 1994). Learning takes place best when unhampered by the need to unlearn knowledge that is embedded, for example, within prior organizational routines (Attewell, 1992; Autio et al., 2000; Cohen \& Levinthal, 1990; Nonaka, 1994). It was also evident that there were a number of organizational routines that the IJV found were difficult to modify and unlearn, closely linked with the cultures of the two countries:

\footnotetext{
What I have found is in Korea, the way of meeting management is very different and the hierarchy is very different. In the UK, for example, you may, if you are a junior, you may still be willing to challenge and challenge your boss publicly. But in Korea it is very different way of influencing. [...] In the UK, we have a culture that in any levels to able to speak your mind and say what you think. In Korea, I found it tends to be a lot more respectful of seniority in the company and actually never cause anyone or any levels embarrassment in the meeting. I always take the argument outside of meeting, deal with it on a one to one basis and I think you need to adapt to that way of working quite quickly. It means that in a short term, the decision making can feel slow. [...] In England, we work very much individually, In Korea, it is much more team focused to make team decisions. [H2]
}

The structural setting interlinked with the managers' individual orientations in critical ways. The autonomy offered to Homeplus managers helped new knowledge to develop; presenting a key learning advantage for Homeplus over IJVs over many subsidiaries, beyond the much recognized advantage of having two sources of different knowledge. Much IJV research indicates that new knowledge can readily be transferred to or absorbed within an IJV, but has rarely considered the unlearning processes that the IJV may have to face. The challenges faced by the need for unlearning were averted in the Homeplus IJV by its managers having the power to take the knowledge they required from the partners, and use it however they found appropriate, with no attempt by the partners to acquire each other's distinctive knowledge. It is possible that in these circumstances unlearning may be easier in an IJV than in a subsidiary.

Above all, the freedom that can be offered in in IJVs means that learning and the knowledge acquisition can be driven by the IJV managers themselves rather than being driven by the partners. IJV research has tended to focus on knowledge transfer, but the testament of the managers in this case is that it is absorptive capacity building rather than knowledge that is being transferred. As Pellegrini (2003) notes, 'learning how to learn' is significant particularly for retail internationalization process; these managers had started with 
their own distinctive knowledge, but were learning how to learn in a new environment. In this, there were important processes, to which we now turn.

\section{ANALYSIS: THE PROCESSES}

Knowledge transfer, pursued by Tesco involved not only explicit knowledge transfer, but also by "grafting" expert knowledge from key Homeplus managers to other operations:

\footnotetext{
When the new picking control system (PCS) was transferred and launched by Tesco HQ, we (the online business department) developed practical training materials for how to roll out the new PCS in Korea. These training materials were so useful that we facilitated the roll out of these training materials further for Tesco in East Europe and Asia. [I5]

Advanced IT system development in Korea is highly appreciated by Tesco HQ as well as by other international subsidiaries. Homeplus IT managers were often asked to be transferred to Tesco's other operations, for example Tesco Japan, in order to install and facilitate IT systems such as their own POS (point of sale) system. [E2]
}

In addition, technical knowledge and know-how was acquired by grafting in key experts with a depth of retail business know-how and international working from Tesco HQ. Technical knowledge was developed within Homeplus by collaborating with other Tesco's international units, particularly in Bangalore, India.

A lot of operational change managers we work with are based in our office in India which is where we have got some very specific skills we bring out to countries particularly, they are stronger than I am on analytical skills and data. We do a lot of work in India and the UK together. We tend to work in that way. [H2]

To gain specific technical know-how, vicarious learning and grafting processes seemed to be more practical and effective than experiential learning processes (Huber, 1991). This seemed to be because, as Cohen and Levinthal (1990) suggest, existing internal members are needed who hold knowledge of the firm's distinctive requirements, procedures, routines, capabilities and extra-mural connections if specific types of complex and compound technical knowledge are to be efficiently integrated:

Tesco's international manager regularly visits us (commercial department) once every two months. [I4]

We (Homeplus) sometimes do benchmark from Tesco UK. I am working in a New Business department which has been set up recently. We had not done new businesses before and we did not have any data whereas Tesco UK has been pursuing new businesses such as Tesco telecoms, finance and other life style services for years now. So it makes sense to learn from Tesco's new businesses. For this reason, we have exchange assignments where we exchange managers for 6 months or longer to share our expertise. Although these exchange assignments can be costly, it helps us to learn new businesses faster and facilitates effective knowledge sharing. [I2]

IJV research has emphasized the importance of synergies in transferring know-how and learning technology and market knowledge (Patton, 2008), and we found knowledge transfer and learning between partners, both within the IJV and with Tesco's other international operations using highly diverse sources of knowledge. This diversity of learning and knowledge acquisition is much greater than has previously been assumed in IJV research, and supports the argument for using constructs from organizational learning research (Huber, 1991). Consistent with Huber's (1991) constructs and processes related to organizational 
learning, knowledge was acquired internally and externally in searching and noticing in three types: scanning, focused searching and performance monitoring. All these types took place on a daily basis intentionally in order to sense Homeplus's external industry and customer assessments which constantly change:

\begin{abstract}
I usually scan by image processing recent development or refit transformations of other competitors and industry on a daily basis. This is crucial form of learning. [I8]

(I learn and scan) by visiting them (other competitors). I visit the competitors every week, E-Mart, Lotte Mart, Hanaro Club and even several department stores. [H1]

We (Homeplus) often have limited information on our competitors when we analyze them. They tend to be quite closed with their information and figures so what we can do is external searching and analysis. We tend to measure or predict their sales and profits. Then we visit their stores many times. We do fieldwork; we see them visually, observe and scan them. With the field data, we analyze our competitors again. [I6]
\end{abstract}

Focused searching took place when managers or divisions actively searched in a narrow part of the Homeplus's internal and external environment, often in reaction to problems or potential opportunities. Huber (1991) argues that at lower organizational levels, the searching tends to be mostly reactive to problems whereas at higher organizational levels, the majority of searching tends to be a result of proactive managerial initiatives. Performance monitoring was used systematically, assessing to internal standards, and against the expectations of external constituencies and stakeholders (Huber, 1991). Monitoring was carried out by managers within Homeplus with the purpose of improving customer services and performance:

\begin{abstract}
Homeplus is really dedicated to increase the role of marketing. We currently have 120 people working in the marketing department. This number is probably twice or even three times bigger than other competitors. We want to work with a customer base and we want to hear our customer voice and use this to improve our services. We want to monitor our customers regularly and effectively more than the other competitors and we do regular performance monitoring by Customer Insight and Question Time through focus group interviews and surveys. [I8]
\end{abstract}

(When we plan our investment strategies), we (Homeplus) do have to research our competitors by comparing and analyzing their price index. So we analyze our price competitiveness accordingly and plan or modify our targets then we make decisions on price and other investments. [...] We do have a Customer Insight Unit (CIU) where they do the majority of price related research and industry market index. One of them, they do price research at regular bases. They do it weekly. They select key products or items which comprise of sixty to seventy per cent of our overall sales. They research price index weekly and they review our price competitiveness whether we invest more on price or not. [I4]

Capabilities were developed by learning from mistakes, but this is a limited form of learning and other forms of learning are usually needed (Crozier, 1965). Vicarious learning, acquired through a regular schedule of visits to competitors and to different formats of retail companies, was critical:

In the beginning, although we did a bit of Korean market research we relied on the regular store visits to the competitors. Particularly, we visited New Core store frequently to see how they price and stock their products as a benchmark. [S1]

I learnt a great deal when I went abroad to the US (Wal-Mart and Target), Japan (JUSCO), Taiwan (Tesco) and Thailand (Tesco) for trainings. I visited their stores regularly with my team and looked at their store layout, product range, customer range and so on. After several store visits in the US and Japan, I felt confident. The next step was for me to think about Korea and how I should modify what I had learnt to the Korean market. [S1] 
I value learning by visiting stores. I send my team to visit stores regularly at specific times to get new ideas and scanning others' products and services. We do not use the industry index that much. [I4]

Experiential learning, the focus of previous research, was important and was manifested in trial and error processes that allowed problems to be defined adapted and rectified:

\footnotetext{
Learning from experience was important. Training or seminars are useful but they can also be limited. Just knowing something does not translate into knowing things well. You have to experiment and put your knowledge into practice to identify any errors or necessary changes. Trial and error processes are important through continuous learning by experience. [I8]

Learn from your mistakes. I think mainly experiences and trial and errors. I have been learning from my experiences. Everybody makes mistakes in business. But... you have to make sure you don't make too many mistakes. Some people do ten things and make no mistakes. I try to do 100 things and make 5 mistakes and those 5 mistakes are not critical ones. [H1]

My daily routines always involve a continuous cycle of 'trial, pilot test, trial and roll out'. [I8]
}

The theoretical distinction between "learning within a frame of reference and learning a new frame of reference" (Huber, 1991: 93) is significant and evident, in that we witnessed both single-loop and double-loop learning levels within the IJV. Single-loop learning (within a frame of reference) was pursued through grafting and vicariously. Double-loop learning (of new frames of reference) drove absorptive capacity building within the IJVs. Here we see that Homeplus was not just acquiring new knowledge. Rather, in identifying problems and suggesting solutions they were engaged in a continuous learning process that built absorptive capacity, to which we turn next.

Absorptive learning requires not only learning new knowledge and skills but also putting them into practice, an experience that other subsidiaries have also had to do; this is why the other subsidiaries were especially useful. The most significant learning processes therefore involved the development of an organizational learning culture within and around Homeplus:

The Samsung culture has not been keen on sharing knowledge. When Tesco set up the IJV with Samsung, Tesco initially opened up and transferred their expertise and best practices with us (Homeplus) which initiated knowledge sharing processes to develop. [I9]

The learning culture developed because knowledge was being actively pulled in by the IJV managers, in initiatives devised and driven locally by themselves, rather than knowledge being pushed onto the IJV by the partners. Homeplus proactively took charge of its own learning in response to its needs, and Tesco responded to requests with distinctive knowledge and recommendations. Tesco did not instruct as to the learning needed, give unrequested knowledge, or force implementation of its systems or manuals. To 'push' their systems onto the new IJV, Tesco would have to understand or to learn the local culture, so Tesco let the IJV managers take responsibility within the frame of the Group's general initiatives, until they encountered problems they could not solve themselves:

Something comes from interpreting the company strategies, interpretations from headquarters strategies. Some of it comes from coaching, some of it comes from benchmarking, some of it comes from my own ideas or my people's ideas. [H1] 
The patterns were of therefore of absorptive capacity building rather than of knowledge transfer, as the IJV managers learned how to learn in a new environment. These IJV managers took knowledge they needed which had been transmitted by others, and received and (crucially) absorbed this knowledge so they could readily exploit it. The way that the UK expatriates worked within the IJV helped here. Tesco committed only a few UK expatriates to key areas within the IJV; minimizing their numbers ensured that strategy initiation and development resided with the IJV itself:

We don't have many expatriates here. One is the CFO who just joined and we used to have a British CEO. [H1]

\begin{abstract}
I think they (Homeplus managers) have got their own initiatives which relate to the Korean market and their own approach to the customers which we (Tesco HQ) don't want to get to know. Well we want to get to know but we don't want to influence. In order to be successful, you have to get to know the local market. There is a balance. We only try to push consistent systems and consistent processes as they will reduce our cost base but in terms of supporting customers we want to be local. [H2]

We produce and develop our own manuals locally (New Business Development department). Except for a few top managerial issues, Tesco HQ allows us a high level of autonomy. They respect our strategic decisions and they allow us to make our own decisions. [I2]
\end{abstract}

Absorptive capacity building began with facts and knowledge being transferred on request from the IJV partners, and skills and abilities being acquired from grafting and vicariously. This largely depended on the skills and specific knowledge of the partners' managers more than anything else which is again closely linked to their own prior (congenital) knowledge. The Homeplus manager's individual prior international experience become a base for its absorptive capacity building.

Samsung, however, had begun the venture with no retail business experience; internal teams had examined Korean and international retail sectors, and realized they lacked concrete retail market specific knowledge and experience. Samsung had therefore grafted expertise by hiring consultants and retail experts from the US and Japan, who worked with Samsung for two and a half years, developing a retail business format and branding. This experience was critical in providing the IJV managers with a prior knowledge base on which new learning could build.

We then see an internal regenerative process involving double-loop learning for building capacity. In this process, trust between the 'teacher firm' and the 'student firm' has been suggested to be important (Boersma, Buckley \& Ghauri, 2003; Lane et al., 2001). In this case, however, both Samsung and Tesco, because of the way in which the joint venture was structured, considered themselves to be both knowledge absorbing and transferring participants: 
If HQ are based in either in the US or UK, they usually tend to have a higher authority than emerging countries. However, I truly think and believe that our practice (Homeplus) is treated equally in terms of authority and control. Coming from this perspective, the learning process is a win-win situation for both of us and Tesco HQ. Our knowledge and learning loop within Homeplus and with Tesco HQ is well developed and we are very open to sharing our skills and knowledge where possible. [I2]

\section{INTERFACES BETWEEN THE MICROFOUNDATIONS}

We have seen how Homeplus managers learned and acquired capability not only from the HQ of their partners firms, as previous research has tended to assume, but from a variety of sources within and around the structure of the IJV, in complex ways (Gong et al., 2007). This diversity, that included managers in the partners' other international operations, and their own contacts from personal and prior experiences of sources, was important in the process of generating and reinforcing patterns of organizational learning. This structural influence also, however, reflected other structural, individual and process factors; there was complete interlinkage between these microfoundations, as is illustrated in Figure 2.

Structurally, the diversity of sources was effected because Homeplus had addressed the problem of the great differences between its partners by delegating authority to the managers themselves to decide what to do, giving them greater control here than would be normal in other IJV relationships, or in many multinational firms. This would not have been possible or effective, however, if the managers as individuals had not had the capabilities to pursue these sources, and the absorptive capacity to make use of the knowledge that they gained. From the beginning, Homeplus was managed by top executives from Samsung; the CEO now, for example, originally came from Samsung. It developed a team with the cultural similarity of Samsung, but it also included highly experienced retail managers from Tesco to work in key functional teams such as in finance, operational management, business processes, and commercial. While sharing Samsung and Korean culture, in many ways, Homeplus managers felt closer to Tesco than to Samsung.

It was the processes pursued by highly experienced managers with individual capacity and structural autonomy that yielded effectiveness (Newburry et al., 2003). Homeplus managers were engaged, proactive actors in the learning process, and the study identified where and how managers displayed this pro-activeness. Experiential learning, the focus of previous organizational learning and internationalization process research, was important but insufficient for these managers; they used other types of learning as well. Their main learning and knowledge acquisition processes were via vicarious learning and grafting, two approaches to learning which are chosen according to the needs and the contexts (Huber, 
1991). Grafting was especially useful when the IJV had not only to acquire and assimilate knowledge but also to transform and exploit it as well. Only managers with extensive experience, however, are able to lead and undertake this selective externally focused knowledge acquisition.

The emphasis to date on 'knowledge transfer' therefore fails to appreciate the far greater importance, from an IJV's perspective, of absorptive capacity building through learning. The IJV and the partners' managers were learning how to learn in a new environment, a doubleloop rather than a single-loop learning process which put the venture on a new 'learning path'. This was a dynamic process, with managers in different positions following new and diverse routes to knowledge and methods of learning. It was essential to have structural, individual and process microfoundations to enable these to take place. As essential, these had to link together in a coherent way, as Felin et al. (2012) suggest. For example, the Homeplus managers not only needed to have the individual capability and absorptive capacity, but they also needed the structural autonomy and power to use it, and the organizational processes and routines to enable their initiatives to become embedded within the organization as a whole.

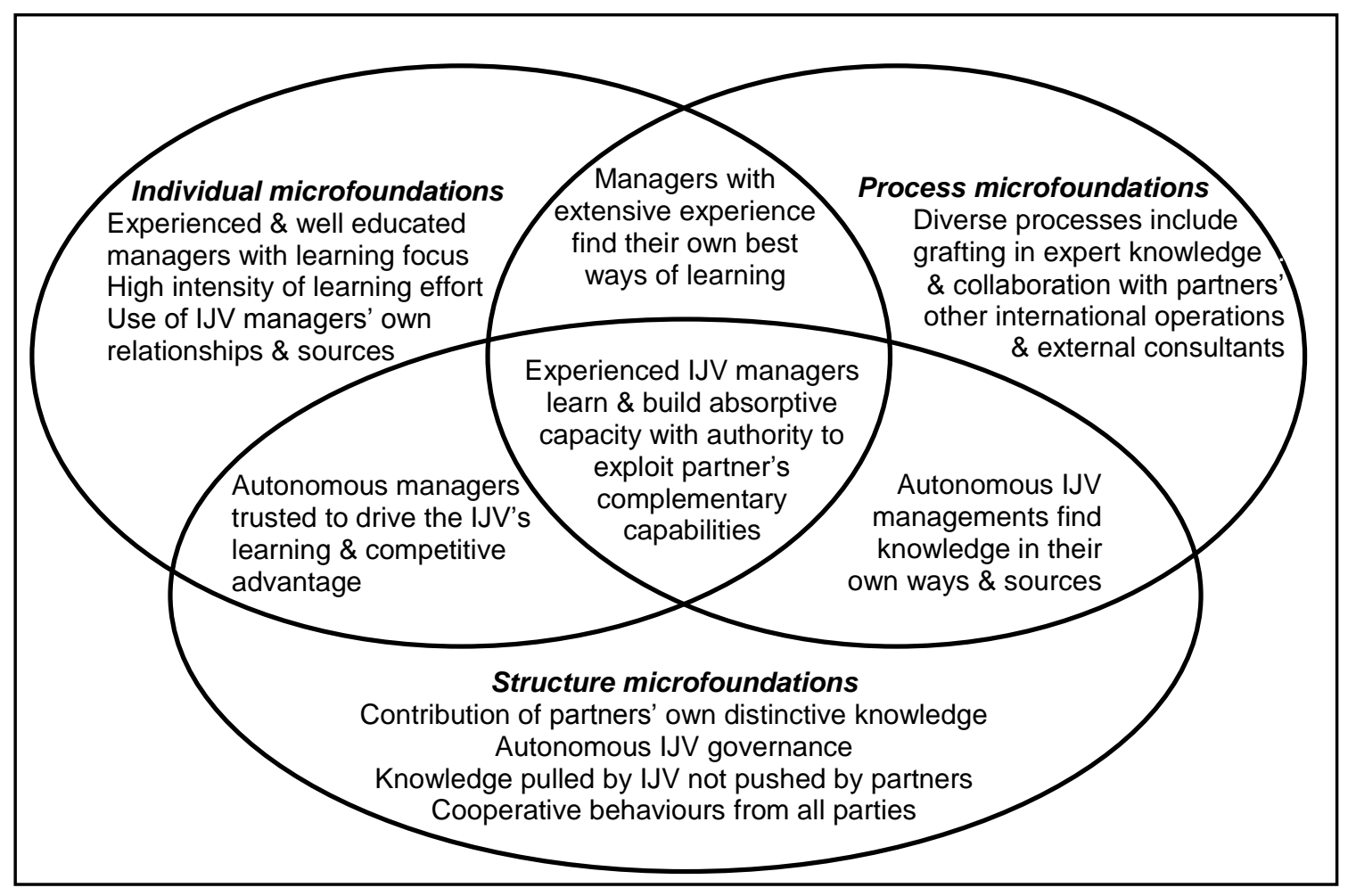

Figure 2: Interlinked microfoundations for IJV learning and absorptive capacity building 


\section{CONCLUSIONS}

The findings of this study are based on a single case study from the retail industry, which limits the generalizability of the results towards other firms and industries. However, the aim of this paper was to gain an understanding of the complexities of learning and knowledge acquisition processes within IJVs rather than to observe generalizeable patterns (Yin, 2009). Future research could add further cases to construct a multiple case study approach that could increase the representativeness of the findings (Gerring, 2007), and allow us to compare and contrast the cases. For example, a question concerns the effects of having different or related partners, and how to manage the IJV in each circumstance; a multiple case study approach might be able to offer explanations on this issue. A deeper understanding of the processes of capability development might best be investigated with a longitudinal approach, which might show how learning develops as the relationships between the partners mature.

The fine-grained nature of this case study, in which we take an IJV manager perspective rather than a partner-level organizational perspective, has, however, responded to Foss et al's (2010) call for research that uncovers deeper complexities in how the managers enact these processes in practice. In so doing, it has contributed to our understanding concerning the types on learning and the sources of knowledge, and concerning the management of learning that builds absorptive capacity. We have found internationalization process theory and organizational learning theory, developed by researchers with different research agendas, to be useful in understanding the activities of managers developing IJVs for the purpose of successful internationalization. These, however, needed to be framed within a theoretical foundation that could embrace the structural, the individual and the process microfoundations behind organizational learning, as has recently been furnished by Felin et al., (2012).

The process of realizing absorptive capacity is challenging, requiring the frames of reference of managers and their organizations to be changed (Huber, 1991). It is especially challenging in IJVs that are created with highly dissimilar partners who can gain the greatest strategic advantages from learning. In Homeplus, the disadvantages of difference were overcome by the IJV managers themselves; it was the managers themselves that drove this intensive process through their own agency, not the partners. It is they that employed the diverse methods of acquiring and sharing knowledge, and chose to use the diverse range of sources that we found. Having been the initiators and creators of knowledge within their IJVs, it is they that shared it with the IJVs' partners as well as with the partners' other international subsidiaries, who all benefited from this process. So it is they that caused the 
learning, knowledge transfer and capacity building processes in IJVs to be broader and richer than we had expected up to now, and it is they and their activities that could be the most useful focus for future research into IJVs. This was only possible, however, because of the microfoundations of appropriate structure, of individual capability, and of creative process which Tesco and Samsung built into the venture.

This study yields some useful implications for the managers of IJVs, where good management has been found to enhance IJV performance (Glaister et al., 2003). The study of this highly successful IJV, with partners from very different industries, clearly shows that there can be great benefits from giving a high level of autonomy to the IJV managers and letting them control their own learning. Indeed, the freedom of managers to learn from diverse sources may well be a key advantage for performance in IJVs over equivalent subsidiaries. In this process, the expertise and experience of the IJV managers themselves is critical: the Samsung-Tesco IJV experience testifies to the benefit of employing highly experienced and motivated managers to IJVs, and giving them the opportunities and freedom to learn as they think appropriate. Managers can regard their IJVs as learning zones, in which the partners' other IJVs or subsidiaries can also benefit from the international business learning that is gained. 


\section{References}

Abell, P., Felin, T., \& Foss, N. (2008). Building micro-foundations for the routines, capabilities, and performance links. Managerial and Decision Economics, 29, 489-502.

Anand, B. N., \& Khanna, T. (2000). Do firms learn to create value? The case of alliances. Strategic Management Journal, 21(3), 295-315.

Anh, P. T. T., Baughn, C. C., Hang, N. T. M., \& Neupert, K. E. (2006). Knowledge acquisition from foreign parents in international joint ventures: An empirical study in Vietnam. International Business Review, 15(5), 463-487.

Argyris, C. (1976). Single and double loop models in research on decision making. Administrative Science Quarterly, 21(3), 363-378.

Argyris, C. (1977). Double loop learning in organizations. Harvard Business Review, 55(5), 115-125.

Argyris, C., \& Schön, D. A. (1978). Organizational learning: A theory of action perspective. Reading, MA: Addison-Wesley.

Argyris, C., \& Schön, D. A. (1996). Organizational learning II: Theory, method and practice. Addison-Wesley, Reading, MA.

Arrow, K. J. (1962). The economic implications of learning by doing. The Review of Economic Studies Ltd. 29(3), 155-173.

Attewell, P. (1992). Technology diffusion and organizational learning- The case of business computing. Organization Science, 3(1), 1-19.

Autio, E., Sapienza, H. J., \& Almeida, J. G. (2000). Effects of age at entry, knowledge intensity, and imitability on international growth. Academy of Management Journal 43(5), 909-924.

Bateson, G. (1979). Mind and nature. Glasgow: Fontana/Collins.

Beamish, P., \& Berdrow, I. (2003). Learning from IJVs: The unintended outcome. Long Range Planning, 36, 285-303.

Beamish, P., \& Delios, A. (1997). Improving joint venture performance through congruent measures of success. In P. W. Beamish, \& J. P. Killing (Eds.), Cooperative strategies: European perspectives (pp. 103-127). The New Lexington Press.

Bhagat, R. S., Kedia, B. L., Harveston, P. D., \& Triandis, H. C., (2002). Cultural variations in the cross-border transfer of organizational knowledge: An integrative framework. Academy of Management Review, 27 (2), 204-221.

Boersma, M. F., Buckley, P. J., \& Ghauri, P. N. (2003). Trust in international joint venture relationships. Journal of Business Research, 56(12), 1031-1042.

Buckley, P. J., \& Casson, M. C. (1988). A theory of cooperation in international business. In F. J. Contractor, \& P. Lorange (Eds), Cooperative strategies in international business (pp. 31-53). Lexington, MA: Lexington Books.

Child, J., \& Faulkner, D. (1998). Strategies of co-operation: Managing alliances, networks, and joint ventures. Oxford: Oxford University Press.

Coe, N. M., \& Lee, Y. S. (2006). The strategic localization of transnational retailers: The case of Samsung-Tesco in South Korea. Economic Geography, 82(1), 61-88. 
Cohen, W. M., \& Levinthal, D. A. (1990). Absorptive capacity: a new perspective on learning and innovation. Administrative Science Quarterly, 35(1), 128-152.

Cohen, W. M., \& Levinthal, D. A. (1994). Fortune favors the prepared firm. Management Science, 40(2), 227-251.

Cohen, W. M., \& Levinthal. D. A. (1989). Innovation and learning - the 2 faces of R-and-D. Economic Journal, 99(397), 569-596.

Crozier, M. (1965). The bureaucratic phenomenon. New York: Oxford University Press.

Daghfous, A. (2004). An empirical investigation of the roles of prior knowledge and learning activities in technology transfer. Technovation, 24(12), 939-953.

Dawson, J. (2001). Strategy and opportunism in European retail internationalization, British Journal of Management, 12(4), 253-266.

De Prijcker, S., Manigart, S., Wright, M., \& De Maeseneire, W. (2012). The influence of experiential, inherited and external knowledge on the internationalization of venture capital firms. International Business Review, 21, 929-940.

Dewey, J. (1987). My pedagogic creed. School Journal, 54, 77-80.

Drucker, P. (1988). The coming of the new organization. Harvard Business Review, 66(1), 45-53.

Eells, R., \& Nehemik, P. (1984). Corporate Intelligence and Espionage. New York: Macmillan.

Eisenhardt, K. M., \& Graebner, M. E. (2007). Theory building from cases: Opportunities and challenges. Academy of Management Journal, 50(1), 25-32.

Eriksson, K., \& Chetty, S. (2003). The effect of experience and absorptive capacity on foreign market knowledge. International Business Review, 12, 673-695.

Eriksson, K., Johanson, J., Majkgard, A., \& Sharma, D.D. (2000). Effect of variation on knowledge accumulation in the internationalization process. International Studies of Management and Organization, 28(2), 337-360.

Feldman, M. S., \& Pentland, B. T. (2003). Reconceptualizing organizational routines as a source of flexibility and change. Administrative Science Quarterly, 48, 94-118.

Felin, T., Foss, N. J., Heimeriks, K. H., \& Madsen, T. L. (2012). Microfoundations of routines and capabilities: Individuals, processes, and structure. Journal of Management Studies, 49(8), 1351-1374.

Fiol, C. M., \& Lyles, M. A. (1985). Organizational learning. Academy of Management Review, 10(4), 803-813.

Fletcher, M., \& Harris, S. (2012). Knowledge acquisition for the internationalization of the smaller firm: content and sources. International Business Review, 21(4), 631-647.

Forsgren, M. (2002). The concept of learning in the Uppsala internationalization process model: a critical review. International Business Review, 11(3), 257-277.

Foss, N. J. (2003). Selective intervention and internal hybrids: interpreting and learning from the rise and decline of the Oticon Spaghetti Organization. Organization Science, 14(3), 331-449. 
Foss, N. J., Husted, K., \& Michailova, S. (2010). Governing knowledge sharing in organizations: Levels of analysis, governance mechanisms, and research directions. Journal of Management Studies, 47(3), 455-482.

Foss, N. J., Laursen, K., \& Pedersen, T. (2011). Linking customer interaction and innovation: The mediating role of new organizational practices. Organization Science, 22(4), 980999.

Gerring, J. (2007). Case Study Research: Principles and Practices. Cambridge University Press.

Ghauri, P. (2004). Designing and conducting case studies in international business research. In C. Welch, \& R. Marschan-Piekkari, Handbook of qualitative research methods for international business (pp. 109-124). Edward Elgar Publishing Limited.

Ghauri, P., \& Grønhaug, K. (2010). Research methods in business studies. Fourth edition. Harlow, UK: Financial times and Prentice-Hall.

Glaister, K. W., Husan, R., \& Buckley, P. (2003). Learning to manage international joint ventures. International Business Review, 12(1), 83-108.

Gong, Y., Shenkar, O., Luo, Y., \& Nyaw, M.-K. (2007). Do multiple parents help or hinder international joint venture performance? The mediating roles of contract completeness and partner cooperation. Strategic Management Journal, 28, 1021-1034.

Gottschalg, O., \& Zollo, M. (2007). Interest alignment and competitive advantage. Academy of Management Review, 32(2), 418-437.

Grandori, A. (1997). Governance structures, coordination mechanisms and cognitive models. Journal of Management and Governance, 1, 29-42.

Groysberg, B., \& Lee, L. E. (2009). Hiring stars and their colleagues: exploration and exploitation in professional service firms. Organization Science, 20, 1155-78.

Guion, L. A. (2002). Triangulation: Establishing the validity of qualitative studies. University of Florida, Extension, Institute of Food and Agricultural Sciences, September, 1-3.

Gupta, A. K., \& Govindarajan, V. (2000). Knowledge flows within MNC's. Strategic Management Journal, 21(4), 473-496.

Hambrick, D. C., \& Mason, P. A. (1984). Upper echelons: The organization as a reflection of its top managers. Academy of Management Review, 9(2), 193-206

Harris, S. (2000). Reconciling positive and interpretative international management research: A native category approach. International Business Review, 9(6), 755-770.

Hedberg, B., Nystrom, P. C., \& Starbuck, W. H. (1976). Camping on seesaws: Prescriptions for a self-designing organization. Administrative Science Quarterly, 21(1), 41-65.

Hennart, J. F. (1988). A transaction costs theory of equity joint ventures. Strategic Management Journal, 9(4), 361-374.

Huber, G. P. (1991). Organizational learning: The contributing processes and the literatures. Organizational Science, 2(1), 88-115.

Hyder A. S., \& Ghauri, P. N. (2000). Managing international joint venture relationships: A longitudinal perspective. Industrial Marketing Management, 29(3), 205-218.

Ingram, P., \& Clay, K. (2000). The choice-within-constraints new institutionalism and implications for sociology. Annual Review of Sociology, 26, 526-546. 
Inkpen, A. C. (2008). Knowledge transfer and international joint ventures: The case of Nummi and General Motors. Strategic Management Journal, 29, 447-453.

Jansen, J. J. P., Van Den Bosch, F. A. J., \& Volberda, H. W. (2005). Managing potential and realized absorptive capacity: How do organizational antecedents matter? Academy of Management Journal, 48(6), 999-1015.

Jepperson, R, \& Meyer, J. (2011). Multiple levels of analysis and the limitations of methodological individualisms. Sociological Theory, 29(1), 54-73.

Johanson, J., \& Vahlne, J.-E. (1977). The internationalization process of the firm: A model of knowledge development and increasing foreign market commitments. Journal of International Business Studies, 8(1), 23-32.

Johanson, J., \& Vahlne, J.-E. (1990). The Mechanism of Internationalization. International Marketing Review, 7(4), 11-24.

Johanson, J., \& Vahlne, J.-E. (2006). Commitment and opportunity development- A note on the internationalization process (IP) model. Management International Review, 46(2), 165-178.

Johanson, J., \& Wiedersheim-Paul, F. (1975). The internationalization of the firm - Four Swedish cases. Journal of Management Studies, 12(3), 305-322.

Kandemir, D., \& Hult, G. T. M. (2005). A conceptualization of an organizational learning culture in international joint ventures. Industrial Marketing Management, 34(5), 430439.

KCCI. (2009). Perspectives from multinational companies in Korea Workshop. InterChamber (Foreign Chambers of Commerce Korea \& Korea Chamber of Commerce \& Industry) Global Career Forum.

Kim, L. (1998). Crisis Construction and organizational learning: capability building in catching-up at Hyundai Motor. Organization Science, 9(4), 506-521.

Kim, T.-G. (2006). Global Top-Tier companies in uphill battle in Korea. The Korea Times, 02/05/2006.

Kogut, B., \& Zander, U. (1992). Knowledge of the firm, combinative capabilities, and the replication of technology. Organization Science, 3(3), 383-397.

Kogut, B., \& Zander, U. (1993). Knowledge of the firm and the evolutionary theory of the multinational corporation. Journal of International Business Studies, 24(4), 625-645.

Kolb, A. Y., \& Kolb, D. A. (2009). Experiential learning theory: A dynamic, holistic approach to management learning, education and development. In S. Armstrong, \& C. Fukami, (Eds.) The SAGE handbook of management learning, education and development. (pp.42-68). London: SAGE.

Kolb, D. A. (1984). Experiential learning: Experience as the source of learning and development. Englewood Cliffs, N.J.: Prentice-Hall.

Kvale, S. (1996). Interviews: An introduction to qualitative research interviewing. Thousand Oaks, CA: Sage.

Kwon, Y.-C. (2008). Antecedents and consequences of international joint venture partnerships: A social exchange perspective. International Business Review, 17, 559-573.

Lane, P. J., \& Lubatkin, M. (1998). Relative absorptive capacity and interorganizational learning. Strategic Management Journal, 19(5), 461-477. 
Lane, P. J., Salk, J. E., \& Lyles, M. A. (2001). Absorptive capacity, learning and performance in international joint ventures, Strategic Management Journal, 22(12): 1139-1161.

Linyanage, S., \& Barnard, R. (2003). Valuing of firm's prior knowledge: A measure of knowledge distance. Knowledge and Process Management, 10(2): 85-98.

Liu, C.-L., Ghauri, P. N., \& Sinkovics, R. R. (2010). Understanding the impact of relational capital and organizational learning on alliance outcomes. Journal of World Business, 45, 237-249.

Lofland, J., \& Lofland, L. H. (1995). Analyzing social settings, (3 ${ }^{\text {rd }}$ ed.) Belmont, Cal.: Wadsworth.

Luo, Y. (1998). Joint venture success in China: How should we select a good partner? Journal of World Business, 33(2), 145-166.

Luo, Y. (2009). Are we on the same page? Justice agreement in international joint ventures. Journal of World Business, 44, 383-396.

Luo, Y., Shenkar, O., \& Nyaw, M-K. (1998). A dual parent perspective on control and performance in international joint ventures: Lessons from a developing economy. Journal of International Business Studies, 32(1), 41-58.

Lyles, M. A. (1988). Learning among joint venture sophisticated firms. Management International Review, 28(4), 85-98.

Lyles, M. A., \& J. E. Salk. (1996). Knowledge acquisition from foreign parents in international joint ventures: An empirical examination in the Hungarian context. Journal of International Business Studies, 27(5):877-903.

Mahnke, V. Pedersen, T., \& Venzin, M. (2005). The impact of knowledge management on MNC subsidiary performance: The role of absorptive capacity. Management International Review, 45(2), 101-119.

Marschan-Piekkari, R., \& Welch, C. (2004). Qualitative research methods in international business: The state of the art, In R. Marschan-Piekkari, \& C. Welch, (Eds.) Handbook of qualitative research methods for international business (pp. 5-24). Edward Elgar: Cheltenham.

Meschi, P.-X., \& Riccio, E.L. (2008). Country risk, national cultural differences between partners and survival of international joint ventures in Brazil. International Business Review, 17, 250-266.

Michailova, S., \& Foss, N. J. (2009). Knowledge governance: themes and questions, In N. J. Foss, \& S. Michailova (Eds.) Knowledge governance: Processes and perspectives (pp.124). Oxford: Oxford University Press.

Miles, M. B. (1979). Qualitative data as an attractive nuisance: The problem of analysis. Administrative Science Quarterly, 24(4), 590-601.

Miles, M. B., \& Huberman, A. M. (1994). Qualitative Data Analysis, Thousand Oaks: Sage.

Minbaeva, D. B. (2005). HRM practices and MNC knowledge transfer. Personnel Review, $34(1), 125-144$.

Morgan, G., \& Kristensen, P.H. (2006). The contested space of multinationals: Varieties of institutionalism, varieties of capitalism. Human Relations, 59(11), 1467-1490. 
Newburry, W., Zeira, Y., \& Yeheskel, O. (2003). Autonomy and effectiveness of equity international joint ventures (IJVs) in China. International Business Review, 12(4), 395419.

Nicolini, D. (2012). Practice Theory, Work and Organization. Oxford: Oxford University Press.

Nonaka, I. (1994). A dynamic theory of organizational knowledge creation. Organization Science, 5(1), 14-37.

Nti, K. O., \& Kumar, R. (2000). Differential learning in alliances. In D. Faulkner, \& M. de Rond (Eds.), Co-operative strategy: Economic, business and organizational issues (pp. 119-134). Oxford: Oxford University Press.

Österberg, P. (2004). Generative learning management: a hypothetical model. The Learning Organization, 11(2), 145-158.

Oviatt, B. M., \& McDougall, P. P. (2005). Defining international entrepreneurship and modeling the speed of internationalization. Entrepreneurship: Theory and Practice, 29(5), 537-553.

Pak, Y. S., Ra, W. \& Park, Y.-R. (2009). Understanding IJV performance in a learning and conflict mediated. International Business Review, 18, 470-480.

Palmer, M. (2005). Retail multinational learning: a case study of Tesco. International Journal of Retail \& Distribution Management, 33(1), 23-48.

Park, B. I. (2011). Knowledge transfer capacity of multinational enterprises and technology acquisition in international joint ventures. International Business Review, 20(1), 75-87.

Park, B. I., \& Ghauri, P. (2011). Key factors affecting acquisition of technological capabilities from foreign acquiring firms by small and medium sized local firms. Journal of World Business, 46(1), 116-125.

Park, S. H., \& Russo, M. V. (1996). When competition eclipses cooperation: An event history analysis of joint venture failure. Management Science, 42(6), 875-890.

Patton, J. R. (2008). Russian federation energy policies and risks to international joint ventures in the oil and gas industry. International Business Research Teaching and Practice, 2(1), 65-84.

Pellegrini, L. (2003). Retail internationalization: an organizing framework. ECR Journal, $3(1), 30-41$.

Penrose, E. T. (1959). The theory of the growth of the firm. New York: John Wiley.

Pentland, B. T. (2011). The foundation is solid, if you know where to look: Comment on Felin and Foss. Journal of Institutional Economics, 7(2), 279-293.

Pentland, B. T., Feldman, M. S., Becker, M. C., \& Liu, P. (2012). Dynamics of organizational routines: a generative model. Journal of Management Studies, 49(8), 1484-1508.

Perry, C. (1998). Processes of a case study methodology for postgraduate research in marketing. European Journal of Marketing, 32(9/10), 785-802.

Porter, M. E. (1980). Competitive strategy. New York, NY: Free Press.

Pudelko, M., \& Harzing, A.-W. (2007). Country-of-origin, localization, or dominance effect? An empirical investigation of HRM practices in foreign subsidiaries. Human Resource Management, 46(4), 535-559. 
Remenyi, D., Williams, B., Money, A. \& Swartz, E. (1998). Doing research in business and management: An introduction to process and method. Sage Publications.

Rugman, A. M. \& Verbeke, A. (2001). Subsidiary-specific advantages in multinational enterprises. Strategic Management Journal, 22(3), 237-250.

Sahal, D. (ed.) (1982). The transfer and utilization of technical knowledge. Lexington, Mass.: D.C. Heath and Co.

Sharpe, D. R. (2004). The relevance of ethnography for international business research. In R. Marschan-Piekkari, \& C. Welch (Eds.), Handbook of qualitative research methods for international business (pp. 306-323). Cheltenham: Edward Elgar.

Siggelkow, N. (2007). Persuasion with case studies. Academy of Management, 50(1), 20-24.

Simon, H. A. (1991). Bounded rationality and organizational learning. Organizational Science, 2(1), 125-134.

Sinkovics, R. R., Penz, E., \& Ghauri, P. N. (2005). Analyzing textual data in international marketing research. Qualitative Market Research: An International Journal, 8(1), 9-38.

Sinkovics, R. R., Penz, E., \& Ghauri, P. N. (2008). Enhancing trustworthiness of qualitative research in international business. Management International Review, 48(6), 689-714.

Steen, J., \& Liesch, P. W. (2007). A note on Penrosean growth, resource bundles and the Uppsala model of internationalization. Management International Review, 47(2), 193206.

Stinchcombe, A. (1991). The conditions of fruitfulness of theorizing about mechanisms in social science. Philosophy of Social Science, 21, 367-388.

Strauss, A., \& Corbin, J. (1998). Basics of qualitative research: Techniques and procedures for developing grounded theory. Sage Publications, Second edition.

Suh, Y.-G., \& Howard, E. (2009). Restructuring retailing in Korea: The case of SamsungTesco. Asia Pacific Business Review, 15(1), 29-40.

Szulanski, G. (1996). Exploring internal stickiness: impediments to the transfer of best practices within the firm. Strategic Management Journal, 17(1), 27-44.

Teece, D. J., \& Pisano, G. (1994). The dynamic capabilities of firms: An introduction. Industrial and Corporate Change, 3(3), 537-556.

Tsai, W. (2001). Knowledge transfer in intra-organizational networks: Effects of network position and absorptive capacity on business unit innovation and performance. Academy of Management Journal, 44(5), 996-1004.

Tsang, A. H. C. (2002). Strategic dimensions of maintenance management. Journal of Quality in Maintenance Engineering, 8(1), 7-39.

Usunier, J.-C. (1998). International and cross-cultural management research. London: Sage.

Westney, E. (2001). Multinational enterprises and cross-border knowledge creation. In: I. Nonaka, \& T. Nishiguchi (Eds.), Knowledge emergence: Social, technical and evolutionary dimensions of knowledge creation (pp. 147-175). Oxford: Oxford University Press.

Winter, S. G. (2003). Understanding dynamic capabilities. Strategic Management Journal, 24, 991-995. 
Winter, S. G. (2011). Problems at the foundation? Comments on Felin and Foss. Journal of Institutional Economics, 7(2). 257-277.

Yao, Z., Yang, Z., Fisher, G. J., Ma, C., \& Fang, E. (2013). Knowledge complementarity, knowledge absorption effectiveness, and new product performance: The exploration of international joint ventures in China. International Business Review, 22(1), 216-227.

Yin, R. K. (1993). Applications of case study research. Applied Social Research Methods Series, 34, Sage, Newbury Park, CA.

Yin, R. K. (2009). Case study research: Design and methods. Fourth Edition. Thousand Oaks, CA: Sage.

Zaheer, S. (1995). Overcoming the liability of foreignness. Academy of Management Journal, $38(2), 341-363$.

Zahra, S. A., \& George, G. (2002). Absorptive capacity: A Review, reconceptualization, and extension. Academy of Management Review, 27(2), 185-203. 